\title{
Engineering agro-food development: The cluster model in China
}

\author{
M. $\mathrm{Yu}^{1^{*}}$, J. Calzadilla ${ }^{2}$, J. L. Lopez ${ }^{2^{*}}$, A. Villa ${ }^{2}$ \\ ${ }^{1}$ Urban Agriculture Research Center, Shanghai Academy of Agricultural Sciences, Shanghai, China; \\ *Corresponding Author: saasyml@126.com \\ ${ }^{2}$ Economy and Social Sciences, Agriculture Faculty UPM, Madrid, Spain; jluis.lopezg@upm.es
}

Received July 2013

\begin{abstract}
The concept of industrial clusters has been around for some time. For many national and regional authorities, particularly in the United States and Europe, cluster development policies became the core for the new development paradigm based on the agglomeration economy. The potential of clusters for the development of a new model for the agro-food industry was recognized at an early stage. Both the United States and Europe have developed a strong base of agro-food clusters. Also in developing countries, where agriculture is the main economical source, a strong ally to change their economy has been found in clusters. Latin America has many good examples of agro-based clusters. The Asian region is now starting to include the agro-food clusters into the mainstream of changes in agriculture, farming and food industry. The case in China is very relevant, as the potential it holds for agro-food development is enormous. In this communication, the state of agro-based clusters in China is described together with two examples of clusters, one specialized in vegetables and other in flowers.
\end{abstract}

Keywords: Agriculture; Development; Clusters; China

\section{INTRODUCTION}

Economic agglomeration is the base of the $20^{\text {th }}$ Century major developments. Either are the urban agglomerations or the industrial districts and clusters, they all provided a new ground for the development of complementarities, substitution effects, and cooperative links between the different industrial and institutional economic actors.

This great competitive advantage has resulted in a reengineering of the way industry, academia, institutions, and policy makers cooperate and work to foster competitiveness in a global economy for the different sectors of the economy. The cluster paradigm has been at the center of the process. National and regional governmental authorities provided sustained support to create, develop and grow clusters in the competitive sectors of their economy, from the earlier cluster initiatives from the United States and Europe, to the world, with important developments in Latin America and Asia.

New tools have been produced to quantify, analyze and study the impact of clusters in employment, competitiveness, knowledge sharing and utilization, R\&D, product output and exports, regional GDP, and others, resulting into the Cluster Observatories in EU and US.

Agriculture, farming and husbandry, and food production are key economic sectors in many economies, and still play an important role in developed ones. It is then natural to extend the cluster model to these sectors, the development of the agro-based clusters.

In this paper, we want to focus in the way the agrobased clusters are taking shape in China, and the results and challenges facing them. Two examples of agro-based clusters in China are considered: one is vegetables production cluster and the other is flowers cluster.

\section{ECONOMIES OF AGGLOMERATION}

Industrial clusters have been around for some time [1], and their influence in the way of engineering a new industrial paradigm is paramount. There is no sector of the economy that has not been influenced by them, and their capability to mobilize knowledge, people, production resources and markets is their characteristic appeal. Agrofood industry is by no way a stranger to this, and clusters are now playing a very significant role in reengineering their horizon.

The cluster model and the industrial district [2] are two forms of effective competitive development for regional industrial economies that implements the benefits 
of economic agglomeration and the Marshallian externalities. The industrial district is a form of economic agglomeration where companies are engaged and linked by similar business activities resulting in a more adaptable production systems better adapted to changing markets [3], which within a geographic area are able to strengthen interactions between local suppliers and customers, shared knowledge and capacities, and build upon existent externalities. The cluster is also as an economic agglomeration model that builds upon knowledge creation, innovation and increasing returns [4] linked to a particular region, where beyond the flow of products there is an exchange of business information and technological expertise.

The economy of agglomeration [5] considers the outcome of an economical system cooperation under a spatial framework such as regional, national or multinational level.

The economic agents in this common space either farms or industries and services prosper developing complementarity and substitution effects. Being, increasing results in production the sign of the exchange between production and transportation costs within the geography.

Marshall [6] considers externalities as a key factor for economic agglomeration providing an encircling effect. The three externalities that more influenced cluster formation are as follows:

1) Distribution in the region of specialize inputs with scale economies linked to the demand.

2) Local availability of specialize labor force, large enough to allow for good matching between jobs and workers.

3) Good flow of ideas and exchange of knowledge, fostering technological spillover and growth.

The analysis of the agglomerations within a region, either in the form of industrial district or cluster, requires the use of different spatial concentration and sector specialization indices that are used to identify the industrial sectors and their economical and employment development.

The more used indices are the Location Quotient (LQ) [7], as a tool for comparing industrial compositions, and the Krugman Index [8], to compare specialization between regions.

The general expression for the Location Quotient of industry $a$ in the region $r$, is given by Eq.1.

$$
L Q_{a}=\frac{X_{a r} / X_{r}}{E_{a} / E}
$$

Where the elements of the equation are the following:

- $X_{a r}$ is the local employment of sector $a$ in the region $r$.

- $X_{r}$ is the total local employment in the region $r$.

- $E_{a}$ is the total reference employment for the industry $a$ in the territory.
- $E$ is the total reference employment in the territory.

The general expression for the measurement of regional specialization using Krugman index is given by Eq.2 comparing two regions A and B.

$$
K I_{A B}=1 / 2 \sum_{i}\left|\left(X_{i A} / X_{A}\right)-\left(X_{i B} / X_{B}\right)\right|
$$

where the elements of the equation are as before.

Figure 1 displays the agriculture cluster for US, and use the quantitative indexes to analyze the spatial distribution. Top employment specialization represents those that the $L Q$ of cluster employment is greater than $75^{\text {th }}$ percentile across all economic areas in the cluster. Top employment share represents national cluster employment that is greater than $90^{\text {th }}$ percentile across all economic areas in the cluster. Top employment specialization and share represent those that meet both criteria.

\section{CLUSTERS REENGINIERING}

\subsection{Cluster Concept}

As mentioned before, clusters emerged as one of the industry realizations of the economy of agglomeration. The term cluster and its inherent characteristics were defined by Porter [1]:

"A geographically proximate group of interconnected companies and associates institutions in a particular field linked by commonalities and complementarities".

Porter used the diamond model [10] of competitive advantage to analyze how the concentration of economic activities in the cluster industries can result in new and better ways to compete and to bring innovation faster to the market [11].

It can be noticed that a cluster is defined by relations not by membership, and the spatial boundaries are as flexible as needed. Another important property of clusters is that they are dynamic and not static over time, but changing continuously.

The OECD [12] has produced a different definition, focused on the knowledge dimension:

"Clusters are characterized as networks of production of strongly interdependent firms, knowledge-producing agents and customers linked to each other in a value adding production chain”.

There is an important difference between the empirical model of clusters and the cluster policies and initiatives oriented to their creation and development.

Cluster policies [11] are specific governmental efforts to support clusters. Those policies include industrial and SME policy, or research and innovation policy. Cluster policies are frequently supported by specific governmental programmes or iniatives. One important actor to this development is cluster organizations. These are legal entities engineering, steering and managing the clusters. 


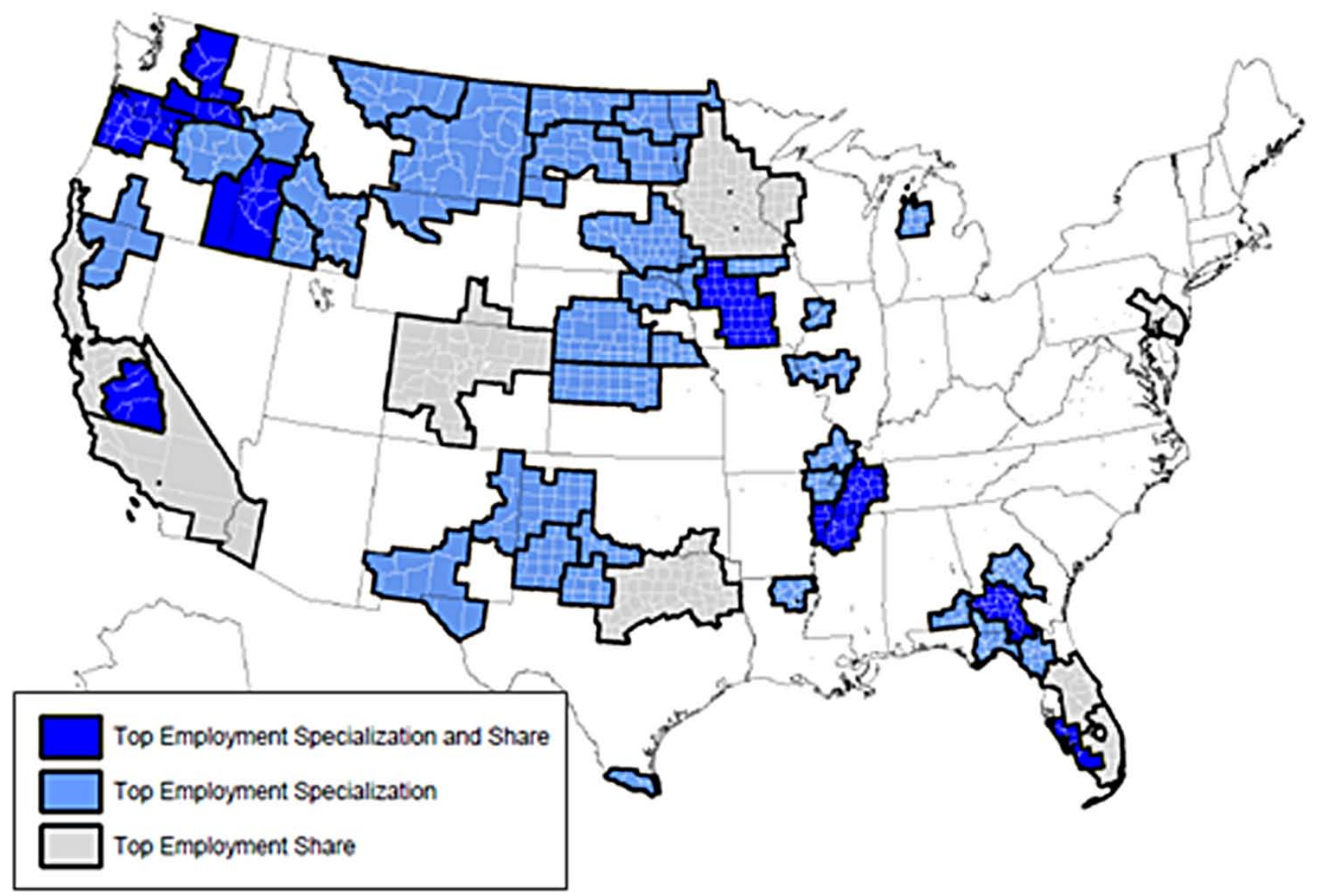

Figure 1. Agriculture Clusters US 2010. Source: Defining Clusters of Related Industries. Delgado, Porter, Stern 2013.

To support these policies, quantitative analysis of growth, decline and emergence of clusters within a territory is needed. This statistical analysis is called cluster mapping. Both EU and US have comprehensive cluster mapping. In the US the Institute for Strategy and Competiveness of the Harvard Business School [13] developed the methodology for the US cluster mapping. In the EU the European Cluster Observatory [11] was established in September 2006 under Europe INNOVA, customized that methodology according to the European codification system and EUROSTAT (European Statistical Services) regional data model.

\subsection{Cluster Components}

The possibility of creation of clusters [14] relies on the geographic proximity of the related economic activities and the presence of co-located end-producers, suppliers, service providers, research laboratories, educational institutions and other specialized institutions.

In the Cluster Initiative Greenbook [15] the organized efforts to develop clusters are grouped as cluster initiatives. These efforts can be organic or planned depending on the process of initiation. The organic clusters are promoted by public bodies, either national or regional gov- ernments, while the planed ones are initiated by private firms that link together in the region to improve their own competiveness by commercial collaboration.

The cluster initiatives involve several objectives in parallel [2]:

1) Human resources upgrading, enhancing the pool of available skills.

2) Cluster expansion, to increase the number of participants.

3) Business development.

4) Commercial cooperation.

5) Innovation.

6) Business environment, to enhance the condition for business.

\subsection{Agro-Based Clusters}

Agro-based clusters [16] are concentrations of producers, agribusiness and institutions engaged in the same agricultural or agro-industry subsector and build value networks addressing common challenges.

These clusters are becoming a competitive factor for the agriculture in the $21^{\text {st }}$ century to address globalization, high-value production, distribution and packaging innovation, and more efficient production. New tools are 
needed to reengineer the new agriculture demands. Central and local governments have realized that agro-based clusters are valuable tools to foster growth in the agricultural sector in their territory, linking them to global value chains [16].

However building agro-food clusters in less developed regions is more challenging, because the sector there is dominated by small-scale producers and organized in a more informal manner, lacking the links to research and innovation, which is difficult for the critical mass needed for growth.

Agro-based clusters in general require focused policies and programmes for their implementation. The roles of multilateral institutions, national governments and overarching institutions are much needed to provide focus and support in the development process.

Some cluster of similar initiatives for the agglomeration of agriculture-based business have been developed, which can be lacking some or part of the cluster characteristics at some point of the agglomeration development. Such initiatives are the following [16]:

1) Agribusiness complexes.

2) Agro-industrial parks.

3) Agri-export zones.

4) Export consortia of food and agricultural products.

5) One-village-one-product.

6) Sub-national Innovation System.

\section{AGRO-FOOD CLUSTERS IN CHINA}

Chinese agricultural sector is at the transitional stage shifting from traditional agriculture towards modern agriculture. Agricultural industrialization has been regarded as one of the most important development strategies to realize the long term goal for agricultural modernization in China. Since the beginning of the $21^{\text {st }}$ Century, particularly after 2003, many scholars started to study agrofood clusters in China [17]. Some scholars believe that agricultural cluster is a development mode of agricultural industrialization, and the development of agricultural cluster is an intrinsic demand for the development of the agricultural sector, also an important approach to the growth of the agricultural sector. In China, the agricultural clusters emerge along with the progress of agricultural industrialization, and agricultural clusters can be regarded as the advanced stage of agricultural industrialization [18].

\subsection{Research on Agricultural Clusters in China}

Compared with the research on agricultural clusters in western countries, the research in China is still at the initial period, and most researches touch upon the definition, formation mechanism, classification of agricultural clusters, and challenges, as well as the role of government in agricultural clusters.

\subsubsection{Formalization Mechanism of Agricultural Clusters}

Some Chinese scholars analyzed the realistic basis and incentives conducive to the formation of agricultural clusters in China. Scaling up of agricultural production, progress in agricultural industrialization, and enhanced entrepreneurship of farmers contributed to the formation of agricultural clusters [19]. Zheng et al. (2006) [20] also found entrepreneurship in rural area played certain role in formation and development of agricultural clusters in China when analyzing the flower cluster in Dounan of Yunnan [20]. In other studies, it was found that agro-food consumption demand is the decisive factor in the formation of agricultural clusters, and market competition is the internal driving force in the formation of agricultural clusters, while difference in agricultural resource endowment lay the basic conditions in the formation of agricultural clusters [21].

\subsubsection{Classification of Agricultural Clusters}

Because of the difference in dominant actor, structure and development environment of cluster, scholars classified agricultural clusters into different development modes/types from different angles. From the angle of organization mode, there are "company + farmer" type, farmer's cooperative coordinated type, dragon head enterprise $^{1}$ leading type, and vertical integration type [22,23]. From the angle of driving force mechanism, agricultural clusters can be classified into agricultural hi-tech park dominant type, market driven type, investment driven type, and specialized small town type [24-26]. From the angle of specific sectors, agricultural cluster can be classified into crop farming cluster, livestock farming cluster, agricultural product processing cluster, agricultural product distribution cluster, and agricultural sci-tech cluster [27].

\subsubsection{Challenges to Agricultural Clusters}

The development of agricultural clusters in China is still at the initial stage, according to some scholars $[18,28$, 29], main challenges to agricultural clusters are summarized below:

1) The agricultural cluster does not have its distinct regional characteristics, often with the same or similar pillar industry which results in over competition within the cluster due to the same industrial structure;

2) There is still a lack of agricultural dragon head en-

${ }^{1}$ Agricultural dragon-head enterprise is defined as a company which is mainly specialized in processing or distribution of agricultural products and can organize and lead farmers access to market. The company is entitled as a dragon-head enterprise only after being certified by governmental authorities under the qualifications of production scale and business performance. 
terprises which have strong market competitiveness and strong capacity to organize a larger number of smallscaled farmers for a market-oriented production;

3) The capability for technological innovation in the agricultural cluster is still weak, and the level of technology is still at low level;

4) The internal organization capability of the cluster is weak, difficult to create an internal beneficial business environment. There is a lack of cooperation among actors in the agricultural cluster. The inter-connection relation is not well established, decreasing the synergistic effect of the cluster;

5) Agricultural enterprises often have difficulties of financing from financial institutions. The supporting institutions and communal service system are not well established.

\subsection{Cases of Agricultural Clusters}

Along with the development of agricultural economy and the change of agricultural development mode, the phenomenon of clustering of agricultural industry has emerged in many places in China, notably, vegetable cluster in Shouguang of Shandong Province, tea cluster in Anxi of Fujian Province, flower cluster in Chenggong of Yunnan Province, sugar cluster in Guixian of Guangxi Province, garlic cluster in Jinxiang of Shandong Province. These agri-food based clusters are all based on one type of agricultural product, with concentration of specialized producers, processors, input suppliers, transportation provider, intermediary agents, research organizations, service institutions and other supporting institutions [30].

Two cases are provided below with special attention to the role of local government (provincial, municipal, and county level) and the role of market system in fostering agricultural clusters, because the governments at various levels and the establishment of market system have played indeed important roles in the development of agricultural clusters.

\subsubsection{Vegetable Cluster in Shouguang}

Shouguang, located in the middle of the Shandong Peninsular, now is the most famous vegetable production area in China. It is well-known as the "Hometown of Chinese vegetable", and also defined by the Shandong Provincial Government as the pilot city for agriculture modernization. In 2012, the vegetable production area is around 56,000 ha and the annual vegetable output is about 7 billion $\mathrm{kg}$.

\section{Formation and development of cluster}

Shouguang area has a very long history of vegetable production. Before 1989, vegetable production was mostly in open field, with very few very simple plastic tunnels. The total vegetable production area was only about 3000 ha.

In 1989, a vegetable famer in Shouguang invented a structure of plastic tunnel in which vegetables can be grown without heating during winter season. From 1989 to 1995 , the plastic tunnels have mushroomed in Shouguang and protected cultivation became very popular. The vegetable varieties used in crops, scale and volume of production and economic return increased greatly, and Shouguang vegetables became very famous in China.

Since 1995 until now, the growth of vegetable sector has been shifted from production expansion to quality improvement, because of change in demand from both foreign and domestic markets. Moreover, the increasingly concern on food safety and environmental issues from the government and the public certainly impacted the development of the vegetable cluster in Shouguang into a more environmental-friendly and sustainable way.

The spatial distribution of agricultural companies and the inter-connected companies and supporting institutions shows that vegetable producers, processors, trading center, distribution center, quality inspection center and so on, in general, are geographically concentrated along the main roads in Shouguang City center and its suburban area [31]. Along with the growth of the vegetable industry in Shouguang area for over two decades, the clustering effect was created, and now Shouguang has the most famous vegetable cluster in China. The Shouguang Vegetable Wholesale Market is the most famous vegetable wholesale market in China, the most important vegetable distribution center in term of its distributing volume, and also the vegetable price formation center and information center.

\section{Role of the government in agriculture cluster}

The government's cornerstone role in guiding the development of the vegetable sector greatly contributes to the development of Shouguang vegetable cluster.

In 1990s, the Shouguang Municipal government's strategy was to fully utilize its favorable natural resources and advantage of long history of vegetable production, and to prioritize and support vegetable production in the process of restructuring its agricultural sector. In the past two decades, several key works have been implemented with the support from government to accelerate the formation and development of the vegetable cluster, including readjusting crop farming structure and expanding vegetable production scale; improving infrastructure for agricultural production; introducing new technology and new variety, improving output efficiency; implementing standardized production, improving vegetable quality; attracting investment, establishing agricultural "silicon valley"; establishing market system, improving distribution efficiency.

In Shouguang area, a number of companies from home and abroad specializing in vegetable breeding, produc- 
tion, processing, and marketing are concentrated in the agricultural hi-tech corridor established by the government, and also a number of Chinese research institutions, field stations, and research centers specializing in vegetable research are established in Shouguang.

With the financial and institutional support from the governments, through public-private collaboration, a wellestablished market system has been set up in the past two decades, which greatly pulls the growth of the vegetable cluster. In addition, the governments also support the development of dragon-head enterprises, marketing association, marketing consortium, agent company and other intermediary organizations which play a very important role in organizing farmers accessing to market.

\subsubsection{Flower Cluster in Chenggong}

The Dian Lake area in the Yunnan-Guizhou Plateau, together with Columbia, Ecuador, and Kenya, are regarded as the best places for cut flower production. Chenggong County, neighboring to the Dian Lake, has become a flower production and distribution center in China, the birthplace of a flower cluster emerging in the past three decades.

\section{Formation and development of cluster}

Growing vegetable is a way of making a living for most villagers living in Dounan Village of Chenggong County, 12 KM from Kunming, the capital city of Yunnan Province. In 1983, a villager planted about $200 \mathrm{~m}^{2}$ of gladiolus in his vegetable field and amazingly he made RMB 3000 yuan by selling the flowers which was a very big amount of money at that time. Then in the next two decades, the floriculture sector in Chennggong County has boosted a tremendous growth in terms of its production scale, trading volume, upgrade of production facilities, improvement of technologies and quality.

From Dounan village a clustering effect and a complete chain have been formed, not only cut flower growers, but also a large number of companies specializing in seedling, bulb, irrigation facilities, greenhouse, and horticultural products are concentrated in Dounan area. Along with the formation and solidification of its central position for cut flower production and distribution in China, Chenggong has also attracted traders from other provinces come to sell pot plants, bonsais, and nursery trees. A number of agriculture associated, supporting and service companies flooding into Chengong market area, such as agricultural input suppliers, logistics service providers, businesses providing cold storage, packaging and so on.

\section{Role of market system in agriculture cluster}

At earlier stage, farmers sold flowers at the roadside market. In 1995, the first flower market with an area of 0.8 ha was set up by the Chenggong County Government, which was the first village level flower market in China.
Then in 1999, the Chenonggong County Government invested to build Dounan Flower Market with 6 ha, because of the fast growth of trading volume. In 2002, an international flower auction market with 12 ha was set up in Dounan. In 2010, with the public-private collaboration and co-investment, the construction of Dounan Flower Industry Park with 70 ha was started, and this park will further boost the development of the flower cluster. The construction and expansion of market system greatly accelerated the growth of flower cluster in Chenggong and also the floriculture sector in whole province.

After 20 years' development, Dounan Flower Market has become the largest flower trading market and distribution center in China in term of trading volume, trading value, export value and flow of traders, and the market also plays determinant role in price setting in Chinese flower market. In 2011, the flower trading value in Dounan Flower Market was RMB 3.6 billion yuan, and 70\% percent of cut flower in Chinese market was from Dounan. The flower traded in the market not only from Yunnan Province, but also from other areas in China as well as from neighboring foreign countries. The brand "Dounan Flower" is valued at RMB 3.2 billion yuan.

\section{RESUME: CHINESE PERSPECTIVE}

At present, the agricultural development in China is under a new scenario, with resources constraints, rigid demand growth of agricultural products, and fiercer market competition, which will bring greater challenges to guarantee stable supply of agricultural products and to improve the quality of agricultural products, as well as to improve the competitiveness of the agricultural sector and the capability for sustainable development.

The governments at various levels have continuously supported the development of agricultural industrialization and modernization which have created an enabling environment and sound foundation for the development of agricultural clusters. In the past decade, China implemented the "Regional Distribution Planning of Advantageous Agricultural Products ${ }^{2}$ (2003-2007)” throughout the country and has obtained remarkable preliminary achievements in the regional distribution of agricultural production and the construction of industrial belts of advantageous agricultural products. The concentration degree of production of crops and livestock in the planned regions become higher and higher. In 2008, China announced the "Regional Distribution Planning of Advantageous Agricultural Products (2008-2015)”, which will further concentrate the agricultural production factors and resources into the planned regions.

\footnotetext{
${ }^{2}$ Advantageous agricultural product is defined as the agricultural product which China has favorable production conditions, with large volume of commodity, good market potential and competitiveness in domestic and international market.
} 
In China, it is a consensus that developing agricultural cluster has been an important approach and inevitable choice to enhance the comprehensive agricultural production capacity and the competitiveness in the agricultural sector, and the strategy of further developing agricultural clusters can make important contribution to the prosperity of rural economy and regional economy. It can be foreseen that in the future the agricultural clusters in China will be optimized in scale and structure, operation mechanism, technology enhancement, and resource mobilization.

Regarding the research on agricultural clusters, until now, most of the researches conducted are qualitative studies but very few quantitative studies. Further field investigation on agricultural clusters is needed, in order to give appropriate and practical advice and suggestions to policy makers and the practitioners in agricultural sector.

\section{REFERENCES}

[1] Porter, M.E. (1998) Clusters and the new economy of competition. Watertown: Harvard Business Review, 76, 77-90.

[2] Sölvell, O. (2008) Clusters. Balancing Evolutionary and Constructive Forces. Ivory Tower Publishers, Stockholm

[3] Piore, M.J. and Sabel, C.F. (1984) The second industrial divide-Possibilities for prosperity. Basic Books, New York.

[4] Krugman, P.R. (1991) Geography and trade. MIT Press, Cambridge, Massachusetts.

[5] Fujuita, M. and Thisse, J.F. (2002) Economics of agglomeration. Cambridge University Press, Cambridge, UK.

[6] Marshal, A. (1920) Principles of economics. Macmillan, London

[7] Combes, P.P., Mayer, T. and Thissie, J.F. (2008) Economic geography, the integration of Regions and Nations. Princeton University Press, Princeton, New Jersey.

[8] H.C. Davis (1990) Regional impact analysis and project evaluation. UBC Press, Vancouver.

[9] Dixon, R. and Freebain, J. (2007) Trends in regional specialization in Australia. Department of Economics, University of Melbourne, Australia.

[10] Porter, M.E. (1985) Competitive advantage. The Free Press. Simon \& Schuster Inc, New York.

[11] European Commission (2008) The concept of clusters policies and their role for competitiveness and innovation. Staff Working Document SEC (2008) 2637, Commission of the European Communities, Luxembourg.

[12] Roeland, T. and Den Hertog, P. (1999) Boosting innovation, the cluster approach. OECD Proceedings, Publication Services, Paris.

[13] Porter, M.E. (2003) Cluster mapping project. http://clustermapping.us
[14] Ketels, C., Sölvell, O., et al. (2006) Clusters in the EU-10 new member countries. European Commission DG Enterprise and Industry, Brussels.

[15] Sölvell, O., Linqvist, G. and Ketels, C. (2003) The cluster initiative greenbook. Ivory Tower, Stockholm.

[16] Gálvez-Nogales, E. (2010) Agro-based clusters in developing countries: Staying competitive in a globalized economy. Occasional Papers No. 25, FAO-Agricultural Management, Marketing and Finance, Rome.

[17] Teng, Z.H. and Wang, H. (2012) Review of the study on Sino-foreign agricultural industrial clusters. Ludong University Journal (Natural Science Edition), 28, 8l-87.

[18] Cao, Q.S., Yan, Z.W., Chu, F. and Tang, Y.B. (2010) The current situation and countermeasure of development of agricultural clusters in China. Jiangsu Agricultural Sciences, 6, 608-610.

[19] Zou, X.S. and Liu, Y. (2007) Study on development of agricultural clusters in China. Issues in Agricultural Economy, S1, 37-40.

[20] Zheng, F.T. and Cheng, Y. (2006) Entrepreneur and formation and evolution mechanism of clusters in Chinese rural area. China Soft Science, 1, 100-107.

[21] You, C., Wei, S.C., Chen, L.Z. and Chen, C.M. (2007) Analysis of and enlightenment from the formation mechanism of agricultural clusters. Fujian Tribune (The Humanities \& Social Sciences Bimonthly), 6, 35-38.

[22] Wang, J.G. (2005) Study on development modes of Chinese agricultural clusters. M.S. Thesis, Shandong University, Jinan.

[23] Wang, Y.R. (2009) The development modes of agricultural clusters. Journal of Anhui Agricultural University (Sco. Sci.), 18, 23-26.

[24] Xiang, H.J., Cao, M.H. and Pan, Z.J. (2005) Agricultural cluster: new approach to development of rural economy. Rural Economy, 3, 47-49.

[25] Gao, F. and Qi, X.H. (2008) Analysis of formation mechanism of Chinese agricultural clusters. Journal of Qingdao Agricultural University (Social Science), 20, 1218.

[26] Zhang, T.H. and Wu, Y.L. (2009) The development mode and evolution mechanism of agricultural clusters. East China Economic Management, 23, 15-18.

[27] Ying, C.J. (2006) Growth of agricultural clusters in the new stage of development. Issues in Agricultural Economy, 3, 5-7.

[28] Xiang, H.J. and Cao, M.H. (2004) The current situation and countermeasures of Chinese agricultural clusters. Journal of Huanggang Polytechnic, 6, 34-36.

[29] Lan, J.H. (2006) Analysis on issues in development of Chinese agricultural clusters based on clustering mechanism. Theory Monthly, 7, 171-173.

[30] Xin, L. (2009). The role of local government in agricultural clusters. Commercial Research, 3, 71-75.

[31] Tan, H.H. (2009) Study on agricultural clusters: Case of Shandong Shouguang Vegetable. Market Forum, 7, 5456. 